University of Nebraska - Lincoln

DigitalCommons@University of Nebraska - Lincoln

Publications, Agencies and Staff of the U.S.

Department of Commerce

U.S. Department of Commerce

$10-2003$

\title{
Stability in The Proportion of Harbor Seals Hauled Out Under Locally Ideal Conditions
}

\author{
Michael Simpkins \\ National Marine Mammal Laboratory, NMFS/Alaska Fisheries Science Center \\ David Withrow \\ National Marine Mammal Laboratory \\ Jack Cesarone \\ National Marine Mammal Laboratory \\ Peter Boveng \\ National Marine Mammal Laboratory
}

Follow this and additional works at: https://digitalcommons.unl.edu/usdeptcommercepub

Part of the Environmental Sciences Commons

Simpkins, Michael; Withrow, David; Cesarone, Jack; and Boveng, Peter, "Stability in The Proportion of Harbor Seals Hauled Out Under Locally Ideal Conditions" (2003). Publications, Agencies and Staff of the U.S. Department of Commerce. 145.

https://digitalcommons.unl.edu/usdeptcommercepub/145

This Article is brought to you for free and open access by the U.S. Department of Commerce at DigitalCommons@University of Nebraska - Lincoln. It has been accepted for inclusion in Publications, Agencies and Staff of the U.S. Department of Commerce by an authorized administrator of DigitalCommons@University of Nebraska - Lincoln. 


\title{
STABILITY IN THE PROPORTION OF HARBOR SEALS HAULED OUT UNDER LOCALLY IDEAL CONDITIONS
}

\author{
Michael A. SimpKins \\ National Marine Mammal Laboratory, \\ NMFS/Alaska Fisheries Science Center, \\ 7600 Sand Point Way NE, \\ Seattle, Washington 98115, U.S.A. \\ and \\ National Research Council, \\ 2101 Constitution Avenue, NW, \\ Washington, DC 20418, U.S.A. \\ E-mail: mike.simpkins@noaa.gov

\section{DAVID E. WITHROW \\ Jack C. Cesarone Peter L. Boveng} \\ National Marine Mammal Laboratory, \\ NMFS/Alaska Fisheries Science Center, \\ 7600 Sand Point Way NE, \\ Seattle, Washington 98115 , U.S.A.
}

\begin{abstract}
We monitored the haul-out behavior of 68 radio-tagged harbor seals (Phoca vitulina) during the molt season at two Alaskan haul-out sites (Grand Island, August-September 1994; Nanvak Bay, August-September 2000). For each site, we created a statistical model of the proportion of seals hauled out as a function of date, time of day, tide, and weather covariates. Using these models, we identified the conditions that would result in the greatest proportion of seals hauled out. Although those "ideal conditions" differed between sites, the proportion of seals predicted to be hauled out under those conditions was very similar $(81.3 \%$ for Grand Island and $85.7 \%$ for Nanvak Bay). The similar estimates for both sites suggest that haul-out proportions under locally ideal conditions may be constant between years and geographic regions, at least during the molt season.
\end{abstract}

Key words: harbor seal, Phoca vitulina, Alaska, radio-tagging, correction factor, haul-out behavior, aerial survey, abundance, generalized additive model, logistic regression.

The number of harbor seals (Phoca vitulina) found ashore varies considerably through time and between sites, as shown by many studies of the haul-out behavior 
of marked individuals (e.g., Huber et al. 2001). Much of this variability may be explained by life history and environmental factors that alter the haul-out behavior of seals (Watts 1996, Frost et al. 1999, Boveng et al. 2003). The number of harbor seals hauled out varies seasonally, generally peaking during pupping and molting seasons (e.g., Brown and Mate 1983, Calambokidis et al. 1987, Jemison and Kelly 2001). This seasonal effect can be quite dramatic over short time periods. For example, the number of seals hauled out can decrease by $85 \%$ in the last three weeks of the molt season (Mathews and Kelly 1996). Harbor seals also tend to haul out in higher numbers during each day around midday and low tide, although the relarive importance of these rwo factors varies between sites (e.g., Allen et al. 1984, Stewart 1984, Thompson et al. 1989, Watts 1996). Inclement weather can also reduce the number of seals hauled out on a given day (e.g., Schneider and Payne 1983, Watts 1992), particularly during the molt season when seals apparently haul out to increase their skin temperature and, thus, molt more efficiently (Feltz and Fay 1966, Boily 1995).

We investigated how much of the variation in the proportion of seals hauled out at two widely separated haul-out sites in Alaska could be explained by measurable factors such as date, time of day, tide, and weather conditions. We adjusted our observations for variations in these factors to derive standardized haul-out proportions that could be compared between sites. We assumed that the relationship between haul-out behavior and environmental conditions varied between geographic regions because harbor seals probably adapt their behavior to local climatic conditions. We chose to standardize our observations to conditions that resulted in the maximal proportion of seals hauled out for each site, which we defined as locally ideal conditions. We hypothesized that harbor seals in all regions would behave similarly under locally ideal conditions, at least at certain times in the seals' life history, such as the molt, because the time spent hauled out may be determined largely by intrinsic physiological constraints (Boily 1995, Brasseur et al. 1996). In other words, we expected the haul-out proportions under locally ideal conditions to be similar between regions.

\section{METHODS}

\section{Study Sites and Remote Data Collection}

This analysis was part of a multiyear study designed to investigate harbor seal haul-out behavior throughout Alaska. The study was conducted at harbor seal haul-out sites during the August-September harbor seal molting season, which coincided with the aerial survey period. The data used in this analysis were from Grand Island in Southeast Alaska in 1994 and Nanvak Bay in Bristol Bay in 2000 (Table 1).

At each site, harbor seals were captured in gill nets $(30-100 \mathrm{~m}$ long, 3-7 $\mathrm{m}$ deep, with 30-cm stretched-mesh openings) set or drifted near haul-out sites (Appendix). Very high frequency radio transmitters (VHF tags; frequency $=164-167 \mathrm{MHz}$ ) were attached to one hind flipper of each seal, and the seals were released at the capture location. One remote receiving station was set up near the haul-out site at Green Island and two stations at Nanvak Bay; each station included a receiving antenna and a data collection computer (DCC). The DCCs were programmed to cycle through each VHF tag frequency once every 15 or $20 \mathrm{~min}$ (varied between years), recording the number of received signals within a 15 -sec sample period. 
Table 1. Haul-out sites, tidal stations, and weather stations incorported into the models of haul-out behavior. Distances are shown between each haul-out site and the tidal and weather stations associated with that site.

\begin{tabular}{llc}
\hline & Grand Island, SE Alaska & Nanvak Bay, Bristol Bay \\
Haul-out site & $54^{\circ} 57.83^{\prime} \mathrm{N}, 132^{\circ} 46.78^{\prime} \mathrm{W}$ & $58^{\circ} 35^{\prime} \mathrm{N}, 161^{\circ} 45^{\prime} \mathrm{W}$ \\
\hline Year monitored & 1994 & 2000 \\
Tidal station & Tlevak Strait: & Estus Point, \\
& Kasook Inlet, Sukkwan Island & Hagemeister Strait \\
& $55^{\circ} 1^{\prime} \mathrm{N}, 132^{\circ} 47^{\prime} \mathrm{W}$ & $58^{\circ} 43^{\prime} \mathrm{N}, 161^{\circ} 8^{\prime} \mathrm{W}$ \\
Weather station & $6 \mathrm{~km}$ & $39 \mathrm{~km}$ \\
& Annette Island Airport & Cape Peirce/Nanvak Bay \\
& $55^{\circ} 3^{\prime} \mathrm{N}, 131^{\circ} 34^{\prime} \mathrm{W}$ & $58^{\circ} 35^{\prime} \mathrm{N}, 161^{\circ} 45^{\prime} \mathrm{W}$ \\
& $78 \mathrm{~km}$ & $0 \mathrm{~km}$ \\
\hline
\end{tabular}

No signals were received if a seal was out of range or at sea with the VHF tag submerged. We analyzed only data recorded more than $24 \mathrm{~h}$ after the last capture event at each haul-out site because we considered it likely that the seals' behavior was abnormal immediately following the disturbance caused by capture events.

Several temporal and environmental covariates were investigated with respect to their effect on the proportion of seals hauled out. Date and local solar time were recorded for each sample period. In addition, tide height, time to the nearest low tide, and tide height relative to the height of the nearest low tide were estimated for every sample period using data from the tide estimation program "WXTIDE32" (http://www.wxtide32.com/). Tidal variables were estimated for the National Water Level Observation Network tidal station nearest to each haul-out site (Hicks 1989, http://www.co-ops.nos.noaa.gov), and Grand Island weather data were collected from National Climatic Data Center (NCDC) archives for the nearest weather station (Table 1). In 2000, personnel of the Togiak National Wildlife Refuge collected weather data at the Cape Peirce/Nanvak Bay field station. We focused our analyses on date, time of day, the three tidal variables, daily precipitation, wind speed, and minimal, maximal, and mean daily temperatures. For Grand Island, wind speed was recorded as average daily wind speed at the weather station near Grand Island. At Nanvak Bay, instantaneous wind speed was recorded at 0800 each day.

\section{Estimating Haul-out Status from VHF Tag Data}

We scaled the recorded number of signals per sample to correct for the effect of transmitters with different transmission rates. We found a strong mode in signals/ sample for each seal, indicating the number of signals normally received when the seal was hauled out. We converted each sample to a scaled signal count (SSC) by setting the modal value of signals/sample for each seal to 1 . SSC values ranged from 0 to 2.0, with a strong peak near 1.0; of the samples with SSC $>0$ (i.e., samples with signals), $52 \%$ had SSC values between 1.0 and 1.2. We considered a seal to be hauled out whenever $0.9 \leq$ SSC $\leq 1.5$. Samples with SSC $<0.9$ may have represented a seal splashing near shore or a seal hauled out in an unusually poor location or orientation. On the other hand, SSC values $>1.5$ may have resulted from other VHF sources, specifically from VHF radio noise from ships nearby. We considered samples with SSC $<0.9$ or SSC $>1.5$ to indicate that a seal was hauled out, only when such samples were recorded in sequence with other samples 
with received signals (i.e., during haul-out bouts). The majority of samples with SSC $<0.9$ or SSC $>1.5$ did occur during such haul-out bouts, therefore seals were scored as "hauled out" during most $(85 \%)$ of these samples.

Occasionally, haul-out bouts (continuous sequences of samples with signals) were interrupted by solitary samples with no received signals (i.e., SSC $=0$ ). We considered these interruptions to represent brief obstructions to the VHF signal rather than brief at-sea periods. Signal obstructions could occur, for example, when a seal's hind flippers were briefly submerged during a rising tide before the seal moved to higher ground. We did consider longer interruptions $(\geq 2$ sequential samples with no received signals) to represent at-sea periods.

Based on the durations between recorded haul-out bouts, we differentiated between "local" at-sea bouts (durations within the normal range) and bouts that could represent a seal out of range (unusually long durations). Harbor seals monitored in this study generally hauled out within range of our receiving antennae at least once per day, thus the duration between haul-out events was almost always less than $24 \mathrm{~h}$ (90\% of cases). On a few occasions, no signals were received from a seal for several days. We removed all such "no-signal" bouts that were greater than $48 \mathrm{~h}$ long from our data analysis (5\% of no-signal bouts) because we suspected that seals hauled out beyond the range of the antennae during these long bouts (average duration of long bouts $=7.6 \mathrm{~d}$ for Grand Island and $5.3 \mathrm{~d}$ for Nanvak Bay). The precise definition of long bouts did not impact the statistical analysis appreciably; analytical results did not change significantly when the definition of long bouts was changed from 48 hours to $24,36,60$, or $72 \mathrm{~h}$.

We also excluded data from seals that rarely, or never, hauled out within range of the receiving antennae (three seals, Appendix). Those seals presumably hauled out almost exclusively at other sites; thus, their true haul-out behavior was not accurately represented by the behavior recorded at the monitored site. One seal's VHF transmitter was continuously heard, suggesting that the transmitter had fallen off onshore (Appendix). We excluded data from this lost transmitter from our analysis. The data from all other seals (excluding long "no-signal" bouts as described above) were transformed into binary format for statistical analysis, with 1 representing a seal hauled out and 0 representing a seal at-sea locally (Appendix).

\section{Statistical Analysis}

We modeled the proportion of tagged seals hauled out as a function of covariates using generalized additive models, which allowed non-parametric relationships between haul-out proportions and covariates (Hastie and Tibshirani 1990). The haul-out proportion data were modeled using the logit link and binomial variance function (McCullagh and Nelder 1989). Although both tide and temperature covariates could be described by three distinct variables, we chose one tidal and one temperature variable for each site's final model to avoid colinearity problems. Thus, each model included six covariates: date, local solar time, daily precipitation, wind speed, one tidal variable, and one temperature variable. The effects of these covariates were modeled as smooth non-parametric functions with a default degree of smoothing that provided up to approximately four degrees of freedom (S-plus $2000,{ }^{1}$ Insightful Corporation, Seattle, WA). The final model for each site was

\footnotetext{
${ }^{1}$ Reference to trade names does not imply endorsement by the National Marine Fisheries Service, NOAA.
} 
chosen as the model with the lowest residual deviance value out of the full suite of possible models with six covariates. This model selection process essentially selected the tidal and temperature covariates that produced the best model when added to the other four covariates. The model output suggested that each of the six covariates significantly improved the model fit in all cases, but autocorrelation present in model residuals caused the GAM procedure to consistently underestimate the residual variance, invalidating the default tests of covariate significance. This autocorrelation did not impact model selection between models with six covariates, but did preclude further selection between models with differing numbers of covariates (e.g., adding or removing covariates in a stepwise fashion). If any covariates in the final models were not significant, the effect of those covariates on the model (and subsequent prediction of haul-out proportions) would have been negligible.

For each covariate in a site's statistical model, we determined the ideal value that resulted in the maximal proportion of seals hauled out. We then predicted the proportion of seals hauled out when all explanatory variables were set at their ideal values (ideal haul-out proportion). We used a bootstrap procedure to estimate the variance around predicted haul-out proportions and to evaluate the effect of variability in behavior between seals. For each bootstrap iteration, we randomly sampled individual seals with replacement to create a bootstrap sample of seals equal in size to the original sample of seals (Grand Island $=33$, Nanvak Bay $=31$; Appendix). We fitted a new generalized additive model (GAM) to haul-out data from the bootstrap sample of seals, using the same six covariates as in the original model for that site. For each covariate in the new GAM, we determined the ideal value that resulted in the maximal proportion of seals hauled out and predicted the ideal haul-out proportion. We repeated this bootstrap procedure 1,000 times for each site, resulting in distributions of ideal covariate values and haul-out proportions from all iterations. These bootstrap distributions were used to estimate the variance around the original predicted values. The shapes of the covariate functions, upon which we based our predictions of ideal haul-out proportions for each bootstrap iteration, were largely immune to the effects of autocorrelation. In contrast, variance estimates provided by the GAM procedure were strongly affected by autocorrelation.

\section{RESULTS}

The final haul-out proportion models for Grand Island and Nanvak Bay varied both in the shape of the covariate functions (Fig. 1,2) and in the ideal values of each covariate (Table 2). The ideal date for Grand Island ( 1 September) was $12 \mathrm{~d}$ before Nanvak Bay's ideal date (13 September). The Grand Island date function had one peak, but the Nanvak Bay function was almost sinusoidal in shape, with two distinct peaks. The solar time functions for both sites were similar, with ideal times around noon. The daily rainfall functions were also similar for both sites, with the largest proportion of seals hauling out on days without rain. Although Nanvak Bay had a larger range of wind speeds, the ideal wind speed was near $10 \mathrm{mph}(16 \mathrm{~km} / \mathrm{h})$ for both sites. However, comparisons between average daily wind speeds (at Grand Island) and instantaneous wind speeds (at Nanvak Bay) must be made with caution.

Different tidal variables were selected in the best model for each site, but minimal daily temperature was selected as best for both sites. Tide height relative to low tide was the best tidal variable for Grand Island, but was the worst tidal 
variable for Nanvak Bay. Similarly, time relative to low tide was the best tidal variable for Nanvak Bay but worst for Grand Island. The ideal relative tide height of $0 \mathrm{~m}$ for Grand Island indicated that the largest proportion of seals hauled out at low tide. In contrast, the largest proportion of seals at Nanvak Bay hauled out more than two hours after low tide. The range of minimal daily temperatures differed between the two sites, making comparisons between the covariate functions at each site difficult. However, the ideal minimal temperature at Grand Island was also the minimum recorded, and the ideal minimal temperature at Nanvak Bay was higher than Grand Island's ideal $\left(5.2^{\circ} \mathrm{F}, 2.9^{\circ} \mathrm{C}\right.$ higher) and much higher than Nanvak Bay's minimum $\left(18.2^{\circ} \mathrm{F}, 10.1^{\circ} \mathrm{C}\right.$ higher $)$.

Repeating the model-fitting and prediction process for 1,000 bootstrap samples of seals quantified the effect of variability between seals on the predicted ideal covariate values and ideal haul-out proportions for each site. Ideal covariate values did vary between bootstrap iterations, but this variation was small when compared to the overall range of observed values for most covariares (Table 2). In some cases, the mean bootstrap value for an ideal covariate value was depressed or inflated (Table 2) because the ideal covariate values in bootstrap iterations were occasionally near a secondary peak in the original covariate function (Fig. 1, 2). For all covariates, the ideal covariate value predicted from the original model was within the interquartile range of the bootstrap values (Table 2). Ideal haul-out proportions varied little among bootstrap iterations for each site; the standard error (SE) of the predicted ideal proportions for Grand Island was 0.047 and 0.022 for Nanvak Bay.

The ideal haul-out proportions predicted for Grand Island (0.813) and Nanvak Bay (0.857) were similar. The ninety-five-percentile range of the bootstrap distribution for Grand Island (0.726-0.904) entirely encompassed Nanvak Bay's 95\% range (0.819-0.903), indicating that the predictions were not significantly different between sites. The statistical models of haul-out behavior, however, differed between sites both in the shape (Fig. 1,2) and ideal values of covariate functions (Table 2). We calculated a pooled ideal haul-out proportion estimate of 0.835 ( $\mathrm{SE}=0.026$ ). The inverse of haul-out proportions are commonly used as correction factors for the proportion of the population at sea and not counted during a survey (e.g., Huber et al. 2001). The inverse of the pooled ideal haul-out proportion, $1.198(\mathrm{SE}=0.039)$, could be used as a correction factor for survey counts similarly adjusted to the number of seals hauled out under ideal conditions (Boveng et al. 2003).

\section{DisCLISSION}

The haul-out models presented here indicated that haul-out proportions under locally ideal conditions were not significantly different between Grand Island (0.813) and Nanvak Bay (0.857), even though those two sites were 970 miles apart and surveyed six years apart. The similar estimates for both sites were consistent with our hypothesis that harbor seals in all regions behave similarly under locally ideal conditions, at least during the molt season. Further validation of the apparent constancy of ideal haul-out proportions will require estimating ideal haul-out proportions for other regions and years.

As we expected, differences in our models between Grand Island and Nanvak Bay indicated that haul-out behavior with respect to environmental conditions did vary regionally. Not only were different tidal variables selected in the best model for 
A) Date $(0=8 / 27 / 94)$

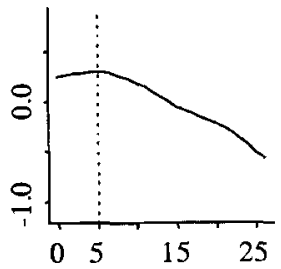

C) Rel. Tide Ht. (m)

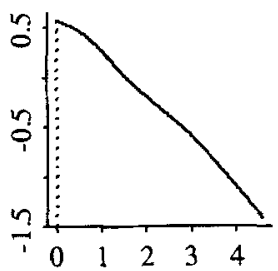

E) Rainfall (in.)

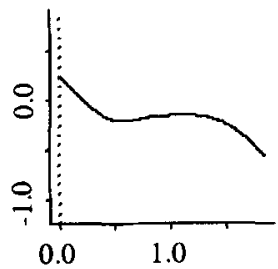

B) Solar time (h)

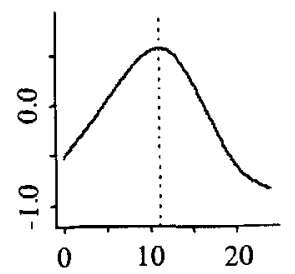

D) Min. Temp. $\left({ }^{\circ} \mathbf{F}\right)$

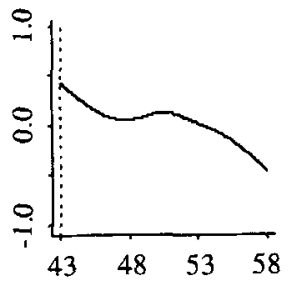

F) Wind (mph)

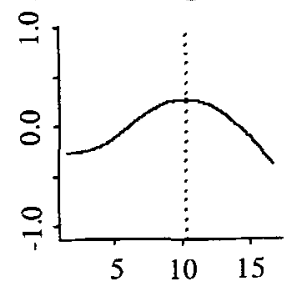

Figure 1. Smooth non-parametric covariate functions for haul-out proportions at Grand Island. The ideal value for each covariate, which resulted in the maximal haul-out proportion, is shown by a dashed line (Table 2). For statistical models, date was coded as the number of days since the start of monitoring (27 August 1994), and minimal daily temperature was scaled as Fahrenheit degrees greater than the lowest temperature observed during monitoring $\left(43^{\circ} \mathrm{F}\right)$. Wind speed data were average daily wind speeds at the Annette Island Airport weather station (Table 1). The $y$-axis in each plot is in relative logit units, with constant scale between plots ( 2 logit units). For a given set of covariate values, the sum of the corresponding logit values and an intercept term $(-0.869)$ gives the predicted logittransformed haul-out proportion.

each site, but the shape of the covariate functions for date and minimal temperature also differed dramatically between the sites' models (Fig. 1, 2). The apparent periodicity in the date function for Nanvak Bay was particularly interesting because it suggested the possibility of two ideal dates at one site (Fig. 2A). In fact, both peaks in the date function were selected as ideal dates during different bootstrap iterations for Nanvak Bay (Table 2). The two peaks may have been related to different ideal dates for individual seals (e.g., different ideals for demographic classes; Thompson and Rothery 1987, Thompson et al. 1989, Härkönen et al. 1999, Daniel et al. 2003), although the periodicity of the date function also coincided with the lunar tidal cycle ( $28 \mathrm{~d}$ between peaks). 
A) Date $(0=8 / 16 / 00)$

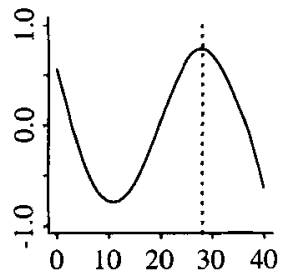

C) Rel. Tide Time (h)

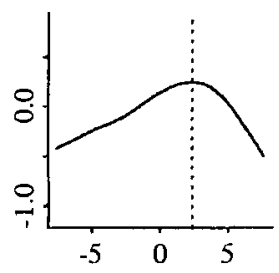

E) Rainfall (in.)

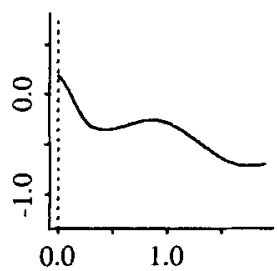

B) Solar time (h)

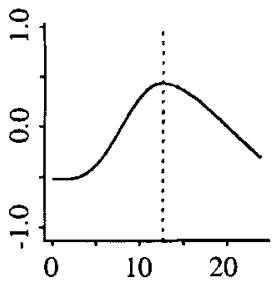

D) Min. Temp. ( $\left.{ }^{\circ} \mathbf{F}\right)$

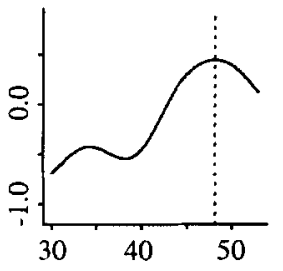

F) Wind (mph)

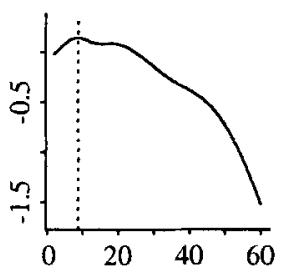

Figure 2. Smooth non-parametric covariate functions for haul-out proportions at Nanvak Bay. The ideal value for each covariate, which resulted in the maximal haul-out proportion, is shown by a dashed line (Table 2). For statistical models, date was coded as the number of days since the start of monitoring (16 August 2000), and minimal daily temperature was scaled as Fahrenheit degrees greater than the lowest temperature observed during monitoring $\left(45^{\circ} \mathrm{F}\right)$. Wind speed data were instantaneous wind speeds at the Cape Peirce/Nanvak Bay field station (Table 1). The $y$-axis in each plot is in relative logit units, with constant scale between plots ( 2 logit units). For a given set of covariate values, the sum of the corresponding logit values and an intercept term $(-0.410)$ gives the predicted logittransformed haul-out proportion.

The differences between the covariate functions for minimal temperature at each site were also interesting (Fig. 1D, 2D), particularly for Grand Island where the ideal minimal temperature was also the minimum recorded. It seems unlikely that harbor seals would prefer to haul out on cold days, especially during the molt season when warm temperatures are thought to accelerate the molting process (Feltz and Fay 1966, Boily 1995). Harbor seals, however, were unlikely to directly assess the minimal daily temperature when deciding to haul-out. The weather covariates, such as minimal temperature and wind speed, should be considered proxies for the actual weather conditions that harbor seals did assess when deciding to haul-out. Without in situ weather stations, we had to rely on these proxy values. The clear relationship between haul-out behavior and both wind speed and minimal temperature 


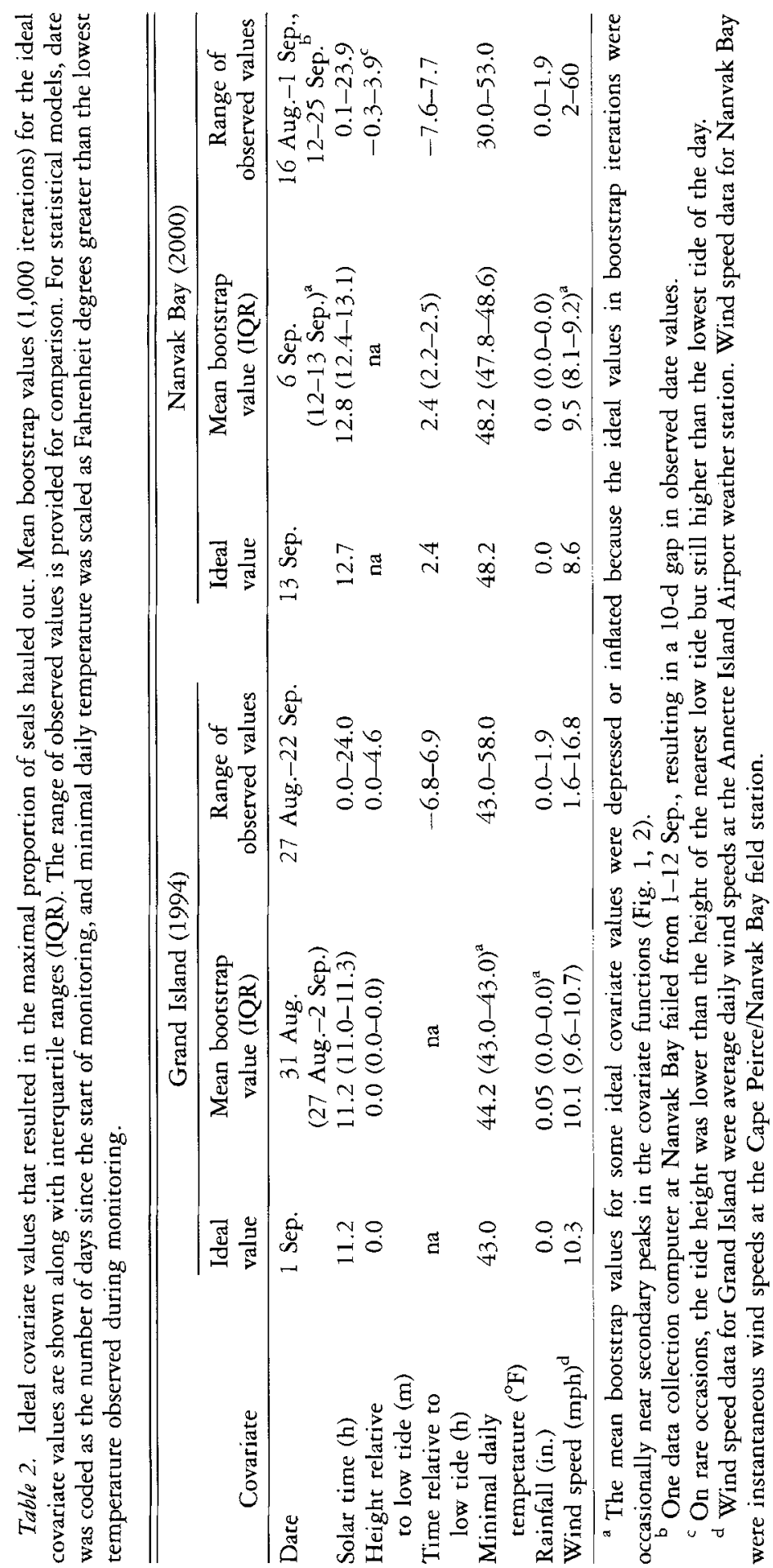


suggested that these proxy values did relate quite well to the decision-making of harbor seals (Fig. 1, 2). If the proxy values were unrelated to harbor seal haul-out behavior, we would have expected our bootstrap samples to predict a wide-range of ideal conditions, rather than the very narrow range of conditions selected during our analysis (Table 2).

The differences in covariate function shapes between the models for the two sites resulted in differences between ideal covariate values for each site (Table 2). We did not expect the same suite of environmental conditions to be ideal for both sites because local climatic conditions vary regionally. We suggest that harbor seals adapt their haul-out behavior to local climatic conditions and haul out in larger numbers as conditions approach ideal for that region.

Ideal conditions are unlikely to occur naturally because all temporal and environmental variables would have to be at ideal levels simultaneously. In this study conditions at Nanvak Bay appeared to come closer to ideal than did conditions at Grand Island. Under the best conditions actually observed during our study at each site, our models predicted that $81.3 \%$ of Nanvak Bay seals and $65.2 \%$ of Grand Island seals would be hauled out (compared to $85.7 \%$ and $81.3 \%$, respectively, when all covariates were set to locally ideal conditions). The maximum actually recorded as hauled out under any conditions during the study was $92 \%$ at Nanvak Bay (10 samples, all in one continuous sequence of $2 \mathrm{~h}$ and $15 \mathrm{~min}$ ) and $84 \%$ at Grand Island (one sample).

Several studies have investigated the relationship between survey counts and environmental conditions at each surveyed haul-out site and have adjusted counts for the effects of environmental covariates (Watts 1996, Frost et al. 1999, Boveng et al. 2003). Our findings suggest that ideal haul-out proportions can be applied to harbor seal survey counts that have been standardized to locally ideal conditions (Boveng et al. 2003). If future research corroborates these findings, the use of ideal haul-out proportions to adjust survey counts could prove to be widely applicable. In other words, the correction factor under locally ideal conditions for Grand Island and Nanvak Bay (1.198) may, in fact, be applicable to similarly standardized harbor seal survey counts from a wide range of harbor seal surveys conducted during the molt season (e.g., Boveng et al. 2003). We do not expect our ideal correction factor to be applicable to surveys of harbor seals outside of the molt season.

Haul-out site fidelity varies between harbor seals, and individuals can use several haul-out sites (Pitcher and McAllister 1981, Yochem et al. 1987, Thompson et al. 1994, Lowry et al. 2001), but the DCCs in this study recorded haul-out events at only one monitored site per year. We chose to include haul-out and local at-sea data from seals that utilized multiple haul-out sites during the study. For example, $80 \%$ of the tagged seals at Nanvak Bay also hauled out at other sites during the study (unpublished data, this study). Some previous haul-out behavior studies included only seals that were known to haul out almost exclusively at the main study site (e.g., Pitcher and McAllister 1981). Surveys of harbor seal populations, however, count all seals hauled out at any given time, not distinguishing between seals that use one or more sites. We used the empirical distribution of signals received from VHF-tags to process and filter the data, removing periods of time when seals probably were using other sites exclusively (Appendix). This filtering process indicated that Grand Island and Nanvak Bay tagged seals spent $50 \%$ and $72 \%$ of their time within range of the receiving antennae (either hauled out or at-sea locally), respectively, and hauled out for $33 \%$ and $40 \%$ of that "local" time (Appendix). Seals were occasionally absent from the monitored haul-out sites for 
long periods (average of $5.3 \mathrm{~d}$ for Grand Island seals and $7.6 \mathrm{~d}$ for Nanvak Bay seals). We suggest that seals moved outside the range of the receiving antennae during these periods, used other haul-out sites for a while, and then returned to the monitored site. Harbor seals are known to move among haul-out sites and perform this kind of site switching behavior (e.g., Thompson et al. 1994, Härkönen and Harding 2001, Lowry et al. 2001). In some cases, seals may switch to using another haul-out site and never return to the monitored site, as happened with three seals from Grand Island (Appendix). It is important to assess the attendance patterns of tagged seals at the monitored site, and to remove periods when the seals are clearly not using the site.

The migration of individual seals between haul-out sites has been problematic for studies of population biology. Migration rates apparently vary with gender and age, leading to variation in the demography of seals between haul-out sites, particularly during the mating season when adult females seem to return to natal sites while juveniles and adult males disperse (Härkönen and Harding 2001). The haul-out behavior of harbor seals also varies with gender and age, including behavior during the molt season focused on by our study (Thompson and Rothery 1987, Thompson et al. 1989, Härkönen et al. 1999, Daniel et al. 2003). The demography of a sample of marked seals, therefore, should reflect the population demography, if the haul-out behavior of the marked sample is to be extrapolated to that population (Härkönen and Harding 2001).

We assumed that our samples of seals at Grand Island and Nanvak Bay were random samples and accurately represented the demographic structure of seals using the monitored haul-out sites. Although our samples may not have reflected the demographic structure of the surrounding population, the samples were not obviously biased (Appendix). Further, our analysis suggested that variability in behavior between individual seals had little impact on the definition of locally ideal haul-out conditions during the molt season. We repeated the model-fitting and prediction process for 1,000 bootstrap samples of seals for each site, and very similar ideal covariate values were chosen for almost all samples, with the notable exception of ideal date for Nanvak Bay (Table 2). More importantly, nearly identical ideal haul-out proportions were predicted for all bootstrap samples; the resulting standard error for predicted ideal haul-out proportions was 0.047 for Grand Island (coefficient of variation, $\mathrm{CV}=0.058$ ) and 0.022 for Nanvak Bay $(\mathrm{CV}=0.026$ ). If the demography of our sample of seals had a strong impact on the covariate functions and predicted haul-out proportions, then we would have expected to observe more variability among the bootstrap samples (each of which presumably had different demographic composition). There was also some concern that the monitoring period at both sites may have occurred after the seasonal peak in haulout numbers; aerial surveys of harbor seals at Nanvak Bay (Jemison $e t$ al. 2001) and near Grand Island (Small et al. 2003) suggested that the seasonal peak occurred at, or near, the beginning of our monitoring period at each site. The date covariate functions, however, indicated that a seasonal peak did occur during the monitoring period at each site.

\section{ACKNOWLEDGMENTS}

For their assistance in the field, we thank B. Fadely, J. Jansen, J. Lewis, E. Mamaev, D. McAllister, V. Nikulin, and J. Thomason. R. MacDonald and staff at the Togiak National Wildlife Refuge provided logistical support for captures at Nanvak Bay and weather 
data from the Cape Peirce/Nanvak Bay field station. J. Laake, G. Pendleton, and J. Ver Hoef provided helpful suggestions and comments at various stages in the analysis. This manuscript was improved by useful comments from J. Bengtson, W. D. Bowen, K. Frost, and $\mathrm{H}$. Huber on earlier drafts. This project received financial support from the National Marine Fisheries Service/NOAA. Animal capture and handling for this study was approved by MMPA permit 782-1355.

\section{Literature Cited}

Allen, S. G., D. G. Ainley, G. W. Page and C. A. Ribic. 1984. The effect of disturbance on harbor seal haul out patterns at Bolinas Lagoon, California. Fishery Bulletin, U.S. $82: 493-500$.

Borly, P. 1995. Theoretical heat flux in water and habitat selection of phocid seals and beluga whales during the annual molt. Journal of Theoretical Biology 172:235-244.

Boveng, P. L., J. L. Bengtson, D. E. Withrow, J. C. Cesarone, M. A. Simpkins, K. J. Frost And J. J. Burns. 2003. The abundance of harbor seals in the Gulf of Alaska. Marine Mammal Science 19:111-127.

Brasseur, S., J. Creuwels, B. Werf and P. Rejjnders. 1996. Deprivation indicates necessity for haul-out in harbor seals. Marine Mammal Science 12:619-624.

BRown, R. F., AND B. R. MATE. 1983. Abundance, movements, and feeding habits of harbor seals, Phoca vitulina, at Netarts and Tillamook Bays, Oregon. Fishery Bulletin, U.S. 81:291-301.

Calambokidis, J., B. L. Taylor, S. D. Carter, G. H. Steiger, P. K. Dawson and L. D. ANTRIM. 1987. Distribution and haul-out behavior of harbor seals in Glacier Bay, Alaska. Canadian Journal of Zoology 65:1391-1396.

Daniel, R. G., L. A. Jemison, G. W. Pendleton and S. M. Crowley. 2003. Molting phenology of harbor seals on Tugidak Island, Alaska. Marine Mammal Science 19:128140.

FelTZ, E. T., AND F. H. FAY. 1966. Thermal requirements in vitro of epidermal cells from seals. Cryobiology 3:261-264.

Frost, K. J., L. F. LoWry and J. M. Ver Hoef. 1999. Monitoring the trend of harbor seals in Prince William Sound, Alaska, after the Exxon Valdez oil spill. Marine Mammal Science 15:494-506.

HÄRKÖNEN, T., K. C. HÅRDING AND S. G. LunNERYd. 1999. Age- and sex-specific behaviour in harbour seals Phoca vitulina leads to biased estimates of vital population parameters. Journal of Applied Ecology 36:825-841.

HÄRKÖNEN, T., AND K. C. HÅRDING. 2001. Spatial structure of harbour seal populations and the implications thereof. Canadian Journal of Zoology 79:2115-2127.

Hastie, T. J., And R. J. Tibshirani. 1990. Generalized additive models. Chapman and Hall, New York, NY.

HICks, S. D. 1989. Tide and current glossary. U.S. Dept. of Commerce, National Oceanic and Atmospheric Administration, National Ocean Service. Rockville, MD.

Huber, H. R., S. J. Jeffries, R. F. Brown, R. L. Delong and G. VanBlaricom. 2001. Correcting aerial survey counts of harbor seals (Pboca vitulina richardsi) in Washington and Oregon. Marine Mammal Science 17:276-293.

Jemison, L. A., AND B. P. Kelly. 2001. Pupping phenology and demography of harbor seals (Pboca vitulina richardsi) on Tugidak Island, Alaska. Marine Mammal Science 17:585600.

Jemison, L. A., G. W. Pendleton and C. A. Wirson. 2001. Harbor seal population trends and factors influencing counts at Nanvak Bay, northern Bristol Bay, Alaska. Pages 5370 in Harbor seal investigations in Alaska. Annual report for NOAA Award NA87FX0300. Alaska Department of Fish and Game, Division of Wildlife Conservation, Anchorage, AK.

Lowry, L. F., K. J. Frost, J. M. Ver Hoef and R. A. DeLong. 2001. Movements of satellite- 
tagged subadult and adult harbor seals in Prince William Sound, Alaska. Marine Mammal Science 17:835-861.

Mathews, E. A., AND B. P. Kelly. 1996. Extreme temporal variation in harbor seal (Phoca vitulina richardsi) numbers in Glacier Bay, a glacial fjord in Southeast Alaska. Marine Mammal Science 12:483-489.

McCullagh P., AND J. A. Nelder. 1989. Generalized linear models. 2nd edition. Chapman and Hall/CRC, Boca Raton, FL.

Pitcher, K. W., AND D. C. MCAllister. 1981. Movements and haulout behavior of radiotagged harbor seals, Phoca vitulina. Canadian Field-Naturalist 95:292-297.

SCHNeIDER, D. C., AND P. M. PAYNe. 1983. Factors affecting haul-out of harbor seals at a site in southeastern Massachusetts. Journal of Mammalogy 64:518-520.

Small, R. J., G. W. Pendieton and K. W. Pitcher. 2003. Trends in abundance of Alaska harbor seals, 1983-2001. Marine Mammal Science 19:344-362.

SteWART, B. S. 1984. Diurnal hauling patterns of harbor seals at San Miguel Island, California. Journal of Wildlife Management 48:1459-1461.

Thompson, P., AND P. Rothery. 1987. Age and sex differences in the timing of the moult in the common seal, Phoca vitulina. Journal of Zoology, London 212:597-603.

Thompson, P. M., M. A. Fedak, B. J. McConnell and K. S. Nicholas. 1989. Seasonal and sex-related variation in the activity patterns of common seals (Phoca vitulina). Journal of Applied Ecology 26:521-535.

Thompson, P. M., D. Miller, R. Cooper and P. S. Hammond. 1994. Changes in the distribution and activity of female harbour seals during the breeding season: Implications for their lactation strategy and mating patterns. Journal of Animal Ecology 63:24-30.

WATTS, P. 1992. Thermal constraints on hauling out by harbour seals (Phoca vitulina). Canadian Journal of Zoology 70:553-560.

WaTTS, P. 1996. The diel hauling-out cycle of harbour seals in an open marine environment: Correlates and constraints. Journal of Zoology, London 240:175-200.

Yochem, P. K., B. S. Stewart, R. L. DeLong and D. P. DeMaster, 1987. Diel haul-out patterns and site fidelity of harbor seals (Phoca vitulina richardsi) on San Miguel Island, California, in autumn. Marine Mammal Science 3:323-332.

Received: 26 January 2002

Accepted: 21 January 2003 
Appendix. Sex and age class of seals captured at each haul-out site (GI = Grand Island, NB $=$ Nanvak Bay), and classification of VHF data collected for each seal. VHF samples were classified as haul-out samples, local at-sea samples, or potentially out-of-range samples. Rare visitor seals $(V)$ rarely or never hauled out within range of receiving antennae and never exhibited the short at-sea bouts indicative of local at-sea behavior (bouts $\leq 48 \mathrm{~h}$ ). One seal ${ }^{L}$ ) apparently lost its VHF transmitter onshore, because the transmitter was continually heard. All data from rare visitor seals and the lost transmitter were excluded from the models of haul-out behavior. All potentially out-of-range samples were also excluded from the haul-out models.

\begin{tabular}{|c|c|c|c|c|c|c|}
\hline Site & Seal ID & Sex & Age class & $\begin{array}{l}\text { Haul-out } \\
\text { samples }\end{array}$ & $\begin{array}{c}\text { Local } \\
\text { at-sea samples }\end{array}$ & $\begin{array}{c}\text { Potentially } \\
\text { out-of-range samples }\end{array}$ \\
\hline GI & 324 & M & Adult & 867 & 1,041 & 0 \\
\hline GI & 346 & F & Adult & 8 & 184 & 1,716 \\
\hline GI & 367 & F & Adult & 233 & 811 & 864 \\
\hline GI & 385 & F & Subadult & 16 & 31 & 1,861 \\
\hline GI & 426 & M & Pup & 25 & 51 & 1,832 \\
\hline GI & 444 & F & Adult & 440 & 1,069 & 399 \\
\hline GI & 464 & M & Subadult & 131 & 212 & 1,565 \\
\hline GI & 487 & F & Pup & 175 & 1,733 & 0 \\
\hline GI & 506 & $\mathbf{M}$ & Pup & 54 & 300 & 1,554 \\
\hline GI & 528 & M & Adult & 510 & 769 & 629 \\
\hline GI & 548 & $\mathbf{M}$ & Adult & 771 & 1,137 & 0 \\
\hline GI & 564 & $\mathbf{M}$ & Adult & 50 & 11 & 1,847 \\
\hline GI & 584 & $\mathrm{~F}$ & Subadult & 282 & 476 & 1,150 \\
\hline GI & $605^{v}$ & $\mathrm{M}$ & Subadult & 15 & 0 & 1,893 \\
\hline GI & 625 & M & Adult & 88 & 115 & 1,705 \\
\hline GI & 644 & $\mathrm{M}$ & Adult & 379 & 1,221 & 308 \\
\hline GI & 664 & M & Adult & 1,328 & 580 & 0 \\
\hline GI & $685^{v}$ & $\mathrm{~F}$ & Subadult & 3 & 0 & 1,905 \\
\hline GI & 705 & F & Subadult & 144 & 372 & 1,392 \\
\hline GI & 727 & M & Subadult & 273 & 364 & 1,271 \\
\hline GI & 747 & $\mathrm{M}$ & Adult & 715 & 1,193 & 0 \\
\hline GI & $765^{v}$ & F & Adult & 0 & 0 & 1,908 \\
\hline GI & 786 & M & Adult & 717 & 1,191 & 0 \\
\hline GI & 804 & $\mathrm{~F}$ & Adult & 82 & 62 & 1,764 \\
\hline GI & 824 & $\mathrm{M}$ & Subadult & 647 & 1,261 & 0 \\
\hline GI & 846 & $\mathrm{M}$ & Subadult & 459 & 1,449 & 0 \\
\hline GI & 864 & F & Adult & 501 & 1,407 & 0 \\
\hline GI & 15 & F & Adult & 47 & 517 & 1,344 \\
\hline GI & 35 & F & Subadult & 155 & 786 & 967 \\
\hline GI & 75 & F & Adult & 133 & 520 & 1,255 \\
\hline GI & 95 & $\mathrm{~F}$ & Adult & 42 & 110 & 1,756 \\
\hline GI & 124 & F & Subadult & 148 & 391 & 1,369 \\
\hline GI & 144 & M & Adult & 119 & 191 & 1,598 \\
\hline GI & 165 & $\mathrm{M}$ & Adult & 192 & 281 & 1,435 \\
\hline GI & 186 & M & Adult & 132 & 76 & 1,700 \\
\hline GI & 203 & $\mathrm{M}$ & Adult & 303 & 1,165 & 440 \\
\hline NB & 6011 & $\mathrm{~F}$ & Adult & 504 & 930 & 1,464 \\
\hline NB & 6111 & M & Subadult & 369 & 710 & 1,819 \\
\hline NB & 6151 & M & Subadult & 392 & 496 & 2,010 \\
\hline NB & 6212 & F & Pup & 344 & 331 & 2,223 \\
\hline
\end{tabular}


Appendix. Continued.

\begin{tabular}{llllrrr}
\hline \hline Site & Seal ID & Sex & Age class & $\begin{array}{c}\text { Haul-out } \\
\text { samples }\end{array}$ & $\begin{array}{c}\text { Local } \\
\text { at-sea samples }\end{array}$ & $\begin{array}{c}\text { Potentially } \\
\text { out-of-range samples }\end{array}$ \\
\hline NB & 6273 & M & Subadult & 1,059 & 1,606 & 223 \\
NB & 6290 & F & Adult & 1,119 & 1,779 & 0 \\
NB & 6331 & M & Subadult & 567 & 709 & 1,622 \\
NB & 6352 & F & Adult & 784 & 2,114 & 0 \\
NB & 6371 & M & Adult & 1,353 & 1,346 & 199 \\
NB & 6392 & F & Subadult & 1,414 & 1,224 & 260 \\
NB & 6411 & M & Adult & 973 & 1,228 & 697 \\
NB & 6434 & M & Pup & 154 & 471 & 2,273 \\
NB & 6452 & F & Subadult & 691 & 787 & 1,420 \\
NB & 6491 & M & Adult & 825 & 1,713 & 360 \\
NB & 6512 & M & Pup & 2,898 & 0 & 0 \\
NB & 6553 & F & Subadult & 507 & 404 & 1,987 \\
NB & 6573 & F & Subadult & 803 & 1,334 & 761 \\
NB & 6591 & M & Subadult & 748 & 1,917 & 233 \\
NB & 6634 & M & Subadult & 1,238 & 1,660 & 0 \\
NB & 6649 & F & Subadult & 720 & 2,178 & 0 \\
NB & 6711 & F & Adult & 2,001 & 897 & 0 \\
NB & 6733 & M & Subadult & 516 & 1,055 & 1,327 \\
NB & 6752 & F & Adult & 1,273 & 1,625 & 0 \\
NB & 6790 & M & Adult & 698 & 1,552 & 648 \\
NB & 6808 & F & Adult & 1,119 & 1,779 & 0 \\
NB & 6833 & M & Adult & 1,103 & 1,795 & 0 \\
NB & 6851 & M & Subadult & 1,037 & 1,009 & 852 \\
NB & 6870 & F & Adult & 1,314 & 1,079 & 505 \\
NB & 6890 & M & Pup & 293 & 950 & 1,655 \\
NB & 6910 & M & Adult & 738 & 555 & 1,605 \\
NB & 6952 & F & Subadult & 803 & 1,522 & 573 \\
NB & 6992 & M & Adult & 526 & 2,372 & 0 \\
\hline & & & & & & \\
& & & & & & 0 \\
\end{tabular}

